Dept. of Parasitlogical,

Fac. Vet. Med., Alexandria Univ., Edfina, Egypt.

Head of Dept. Prof. Dr. K.A. Ashmawy.

\title{
SCANNING ELECTRON MICROSCOPIC OBSERVATIONS \\ ON THE SURFACE TOPOGRAPHY OF GASTRODISCUS AEGYPTIACUS COBBOLD (1876) [TREMATODA: DIGENEA]
}

(With 12 Figrues)

By
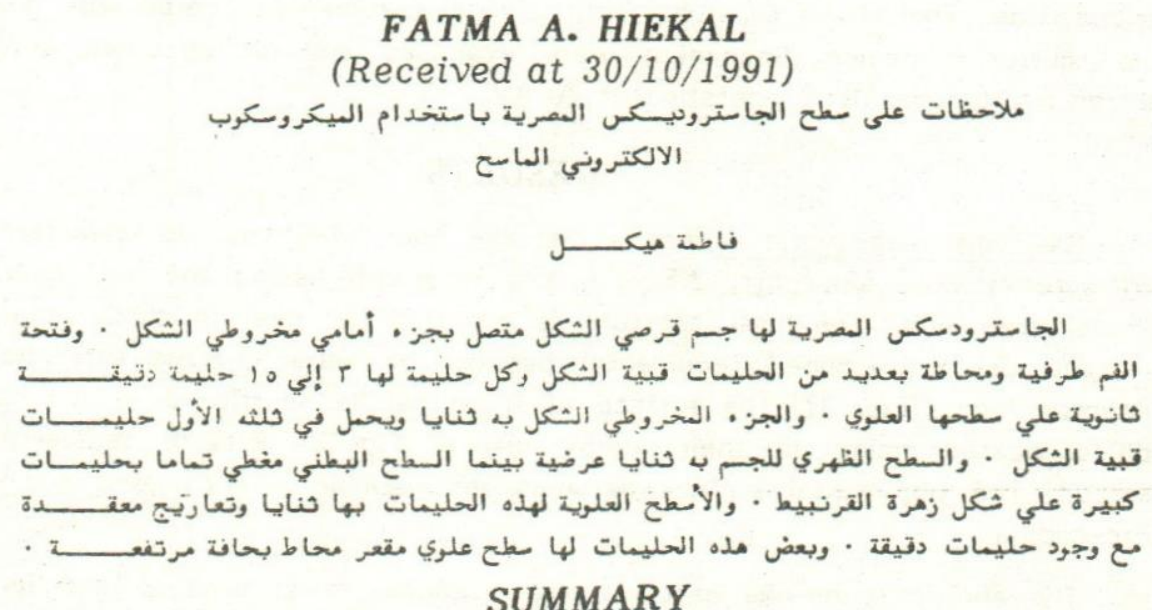

Gastrodiscus aegyptiacus has a disc-like body connected with anterior cone-like part. The oral aperture is terminal and surrounded by numerous jome-shaped papillae, each papilla has $3-15$ secondary micro-papillae locats ${ }^{-1}$ at its apical surface. The cone-like part is folded and carries dome-shaped papillae at its anterior third. The dorsal surface of the body carries transverse folding, while the ventral surface is completely covered by large cauliflower-like papillae. These papillae have complex corrugated apical surface with numerous micro-papillae. Some papillae have concave or depressed apical surface encircled by elevated margin.

\section{INTRODUCTION}

The tegument of digenetic trematodes is a physiologically important interface in the host-parasite relationship (ERASMUS, 1970). With the recent use of scanning electron microscopy (SEM), a new approach has been possible elucidating the ultrastructure and surface features of this interface and to newly interpreting its functionai morphology. A few SEM studies has been reported on amphistomes from mammals (EDUARDO, 1980 a,b.c and TANDON \& MAITRA, 1981, 1982). Similar studies on Gastrodiscus aegyptiacus are non existant to the best of our knowledge. So, the aim of this study was to use the SEM to study the surface microtopography in order to reveal any specific differential characters of the tegument of G. aegyptiacus.

Assiut Vet.Med.J. Vol. 26, No. 52, January, 1992. 


\section{FATMA A. HIEKAL}

\section{MATERIAL and METHODS}

Adult flukes were collected from the large intestine of donkies immediately after been sacrificed in the anatomy hall, Faculty of Vet. Med. Alex. Univ. Egypt, and fixed for $2-4 \mathrm{hs}$. in aqueous $4 \%$ glutaraldehyde/ $1 \%$ osmium tetroxide in a ratio of $3: 1$. The material was washed repeatedly in distilled water and then dehydrated through ethanol and amyle acetate. It was subsequently critically point dried using carbondioxide. Then fixed to stubs with colloidal carbon and coated with gold pallidium in a sputtering device. Specimens were examined and photographed using scanning electron microscope (JEM) operating at $20 \mathrm{KV}$.

\section{RESULTS}

Gastrodiscus aegyptiacus has a disc-like body (7-15 $\mathrm{mm}$ in diameter) connected with anterior cone-like part, $2.5-4 \mathrm{~mm}$ in length having the oral aperture at its terminal free end. The oral aperture is elleptical to oval in shape and surrounded by numerous dome-shaped tegumental papillae of variable sizes arranged nearly in concentric rings (Fig. 1). The surface of these papillae carries 3-15 secondary micropapillae located mainly at their apical surface (Fig. 2). Pits or depressions are also observed. The tegumental surface between the papillae is corrugated and carries also micro-papillae.

The anterior cone-like part increases gradually in diameter towards its connection with the body and is folded (Fig. 3). These folds are large, arranged longitudinaly and faid-out at the oral aperture and at the connection with the body (Fig. 4). In addition to these folds there are small transverse folds near the connection with the body. The surface of the first third following the oral aperture carries dome-shaped papillae which decrease in number gradually towrds the middle third (Fig. S). Dorsally the rest of the cone-like part shows few scattered papillae and many micro-papillae especially near the connection with the body. Ventrally many domed papillae and micro-papillae are present.

The disc-shaped body shows no clear domed papillae at its dorsal surface but micro-papillae are observed. Small transverse folding are the common feature on the dorsal surface (Fig. 6). Areas with smooth irregularity are also observed (Fig. 7).

The ventral surface of the body has the genital opening nearly at its beginning (Fig. 8). This opening is surrounded by a thickened margin baving a genital papilla at its middle. The latter papilla is tapering towards its end where the genital pore lies at the tip. The tegument covering the margin and the genital papilla had domed papiliae with numerous secondary micro-papillae (Fig. 9).

The ventral surface is completely covered by large cauliflower-like papillae located nearly at regular intervals from each other (Fig. 10). These papillae show little variations in size and their free surfaces have complex corrugations with numerous 


\section{SURF ACE TOPOGRAPHY, GASTRODISCUS AEGYPTIACUS}

micro-papillae (Fig. 11). Some papillae have concave, depressed or little bit invaginated apical surface encircled by raised margin. Micro-papillae and corrugations are also found between the large papillae.

The lateral margins of the body are curved ventrally and free from large papillae but with many domed papillae. The acetabulum is shifted a little bit toward the ventral surface (subterminal) (Fig. 12). It has elleptical opening and its rim is wider and more corrugated ventrally than at the dorsal. Domed papillae and numerous micro-papillae are observed on the acetabular surface.

\section{DISCUSSION}

The present study revealed that the tegument of Gastrodiscus aegyptiacus carries dome shaped papillae especially arround the oral aperture and on the first third of the anterior cone-like part. Domed papillae commonly occur in trematodes on their anterior third and at other sites on their bodies. It has been suggested that they have a sensory function SILK et al. (1970), MILLER et al. (1972); MORRIS (1973); BENNETT (1975); NADAKAVUKAREN \& NOLLEN (1975); KUNTZ et al. (1976), SAKEMOTO \& ISHII (1977); BAKKE (1978); BAKKE \& LIEN (1978) and TAND $\overline{O N}$ \& MAITRA (1982). The latter authors added that amongst the rumen amphitomes, the Bilatorchis papillogenitalis has papillae arranged in concentric rings in the oral area and each papilla has 4 to 22 apical knob-like projections. These results come in accordance with the present data where each papilla carries 3-15 secondary micro-papillae. Pits or depressions were also observed on their surfaces. BAKKE (1976 b) discribed such pits and depressions on the domed papillae of Leucochloridium spp. (Digenea).

BENNETT (1975) mentioned that these papillae when present near the mouth could be involved in contact reception during food detection or feeding and those found on the general body surface might function in recording pressure changes as the tegumert stretches.

In the present study, domed papillae were also observed in the region of the genital pore. These papillae probably might have a specific sensory function during sexual reproduction. BAKKE (1976 a,b) and EDUARDO (1980 b) recorded similar findings in Leucochloridium spp. and Orthocoelium indonesiense respectively.

Among the present observations, the tegument of the dorsal surface of the body was characterized by presence of small transverse folding. Such folding was described by EDUARDO (1980 b) and HIEKAL \& HILALI (1991) on Orthocoelium indonesiense and $\underline{P a r a m p h i s t o m u m ~ m i c r o b o t h r i u m ~ r e s p e c t i v e l y . ~}$

The ventral surface of the body was marked by large cauliflower-like papillae having complex corrugated surface with numerous secondary micro-papillae. From the available literature no such papillae were described in trematodes or in other parasites. In addition to the sensory functions, these papillae, in my opinion, might have a role in fixing the parasite to the host tissues. This is explained by the presences of papillae having depressed or invaginated apical surface encircled by elevated margin.

Assiut Vet.Med.J. Vol. 26, No. 52, January, 1992. 
FATMA A. HIEKAL

\section{ACKNOWLEDGMENT}

I wish to thank Prof. Dr. K.l. Ashmawy, the Head of Parasitology Dept. for his support, and I thank the technician of SEM Fac. of Agriculture, Alexandria University for her technical assistance.

\section{REFERENCES}

Bakke, T.A. (1976 a): Shape, size and surfce topography of genital organs of Leucochloridium spp. (Digenea), revealed by light and scanning electron microscopy. Zeitschrift fur Parasitenkunde, 51: 99-113.

Bakke, T.A. (1976 b): Fkunctional morphology and surface topography of Leucochloridium spp. (Digenea) revealed by scanning electron microscopy. Zeitschrift fur Parasitenkunde, 51: 115-128.

Bakke, T.A. (1978): Urogonimus macrostomus (Rudolphi, 1803) (Digenea). Its taxonomy and morphology are revealed by light and scanning electron microscopy. Canadian journal of Zoology, 56: 2280-2291.

Bakke, T.A. and Lien,L. (1978): The tegumental surface of Physllodistomum conostomum (Olsson, 1876) (Digenea) revealed by scanning electron microscopy. International Journal for Parasitology 8: 155-161.

Bennett, C.E. (1975): Surface features, sensory structures and movement of the newly excysted juvenile Fasciola hepatica L. Journal of Parasitology, 61: 886-891.

Eduardo, S.L. (1980 a): Bilatorchis papillogenitalis n.g., n.sp. (Paramphistomidae=Orthocoelinae), a parasite of the red lechwe (Kobus leche Gray, 1850) from Zambia. Systematic Parasitology, 1: 141-149.

Eduardo, S.L. (1980 b): Orthocoelium indonesiense, a new species of amphistome from ruminants in Indonesia. Systematic Parasitology, 1: 203-210.

Eduardo, S.L. (1980 c): A new genus, Leiperocotyle, for Cotylophoron okapi, Leiper, 1935 and C. okapi. Systematic parasitology, 1: 255-263.

Erasmus, D.A. (1970): The host parasite interface of strigeoid trematodes IX: A probe and transmission electron microscope study of the tegument of Diptostomum phoxini Faust, 1918. Parasitology, 61: 35-41.

Fatma Hiekal, A. and Hilali, M. (1991): Scanning electron microscopy of the tegument of two rumen flukes Paramphistomum microbothrium and Cotylophoron cotylophorum (Fischoeder, 1901) in press.

Kuntz, R.E.: Tulloch, G.S.; Davidson, D.L. and Huang, T. (1976): Scanning electron microscopy of integumental surface of Schistosoma haematobium. Journal of Parasitology, 62: 62-69.

Miller, F.H.; Tulloch, G.S. and Kuntz, R.E. (1972): Scanning electron microscopy of integumental surface of Schistosoma mansoni. Journal of Parasitology, 58: 693-698.

Morris, G.P. (1973): Scanning electron microscopy of trematodes embedded for transmission electron microscopy. Journal of Parasitology, 59: 806-809.

Nadakavukaren, M.J. and Nollen, P.M. (1975): A scanning electron microscopic investigation of the outer surface of Gorgoderina attenuata. International Journal for Parasitology, 5: 591-595.

Assiut Vet.Med.J. Vol. 26, No. 52, January, 1992. 


\section{SURF ACE TOPOGRAPHY, GASTRODISCUS AEGYPTIACUS}

Sakemoto, K. and Ishii, Y. (1977): Scanning electron microscope observations on adult schistosoma japonicum. Journal of Parasitology, 63: 407-412.

Silk, M.H.; Spence, J.M. and Buch, B. (1970): Observations of Schistosoma mansoni blood flukes in the scanning electron microscope. South African Journal of Medical Sciences, 35: 23-29.

Tandon, V. and Maitra, S.C. (1981): Steroscan observations of thesurface topography of Gastrothylax crumenifer (Creplin, 1847) Poirier, 1883 and Paramphistomum epiclitum fischoeder, 1904 (trematoda Digene). Journal of Helminthology, 55: 231-237.

Tandon, V. and Maitra, S.C. (1982): Scanning electron microscopic observations on the tegumental surfaces of two rumen flukes (Trematoda: Paramphistomata). Journal of Helminthology, 56: 95-104.

\section{KEY OF FIGURES}

Fig. 1: Scanning electron micrograph showing oral aperture (0) of Gastrodiscus aegyptiacus surrounded by numerous dome-shaped papillae (dp). X 313.

Fig. 2: Domed papillae having secondary micro - papillae (mp) at their apical surface. Pit or depression (p). X 3130.

Fig. 3 \& 4: Scanning electron micrograph showing first half of the anterior cone-like part. It is folded $(F)$ longitudinally and these folds faid-out at the oral aperature (0). $\times 70$.

Fig. 5: Part fromthe first third of the anterior cone-like part showing domed papillae (dp). X 313.

Fig. 6: Scanning electron micrograph showing area from the dorsal surface of the body having transverse folding. $X 468$.

Fig. 7. nea from the dorsal surface having smooth irregularity. $\times 468$.

Fig. 8: Genital opening (go) at the beginning of the ventral surface of the body. Ventral surface (V) of the anterior cone-like part having many domed papillae. X 109.

Fig. 9: Domed papillae and micro-papillae (mp) at the margin of the genital opening. X 2340 .

Fig. 10: Large cauli-flower-like papillae $(c p)$ on the ventral surface of thebody. Papillae having depressed or invaginated apical surface (ip). X 151.

Fig. 11. Cauli-flower-like papillae having corrugated free surface with many micro-papillae. $\times 468$.

Fig. 12: Scanning electron micrograph showing the acetabulum $(A)$ at the posterior end of the ventral surface. Its rim was wide and more corrugated ventrally. Large cauliflower-like papillae (cp). X 70.

Assiut Vet.Med.J. Vol. 26, No. 52, January, 1992. 
FATMA A. HIEKAL
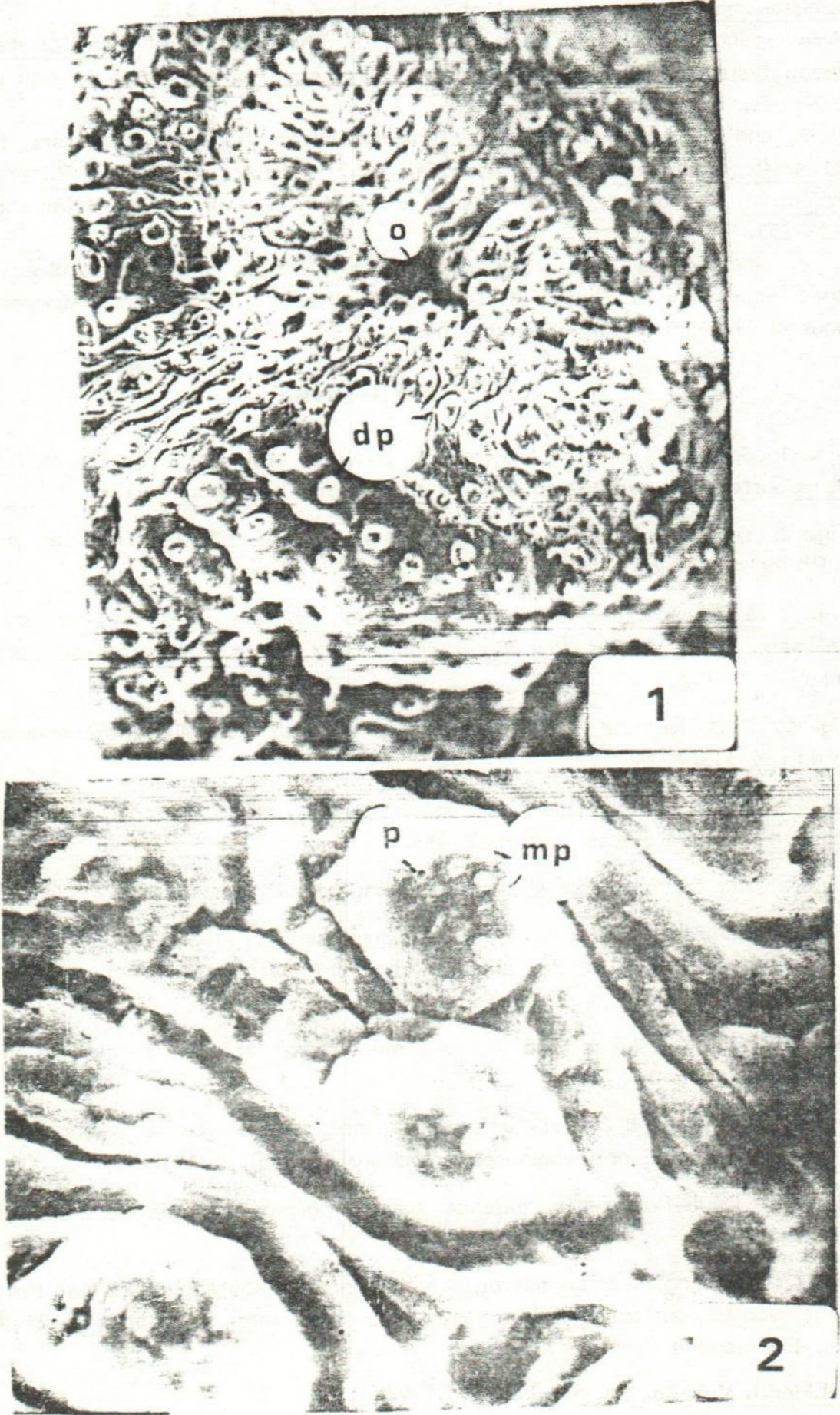

Assiut Vet.Med.J. Vol. 26, No. 52, January, 1992. 
SURFACE TOPOGRAPHY, GASTRODISCUS AEGYPTIACUS
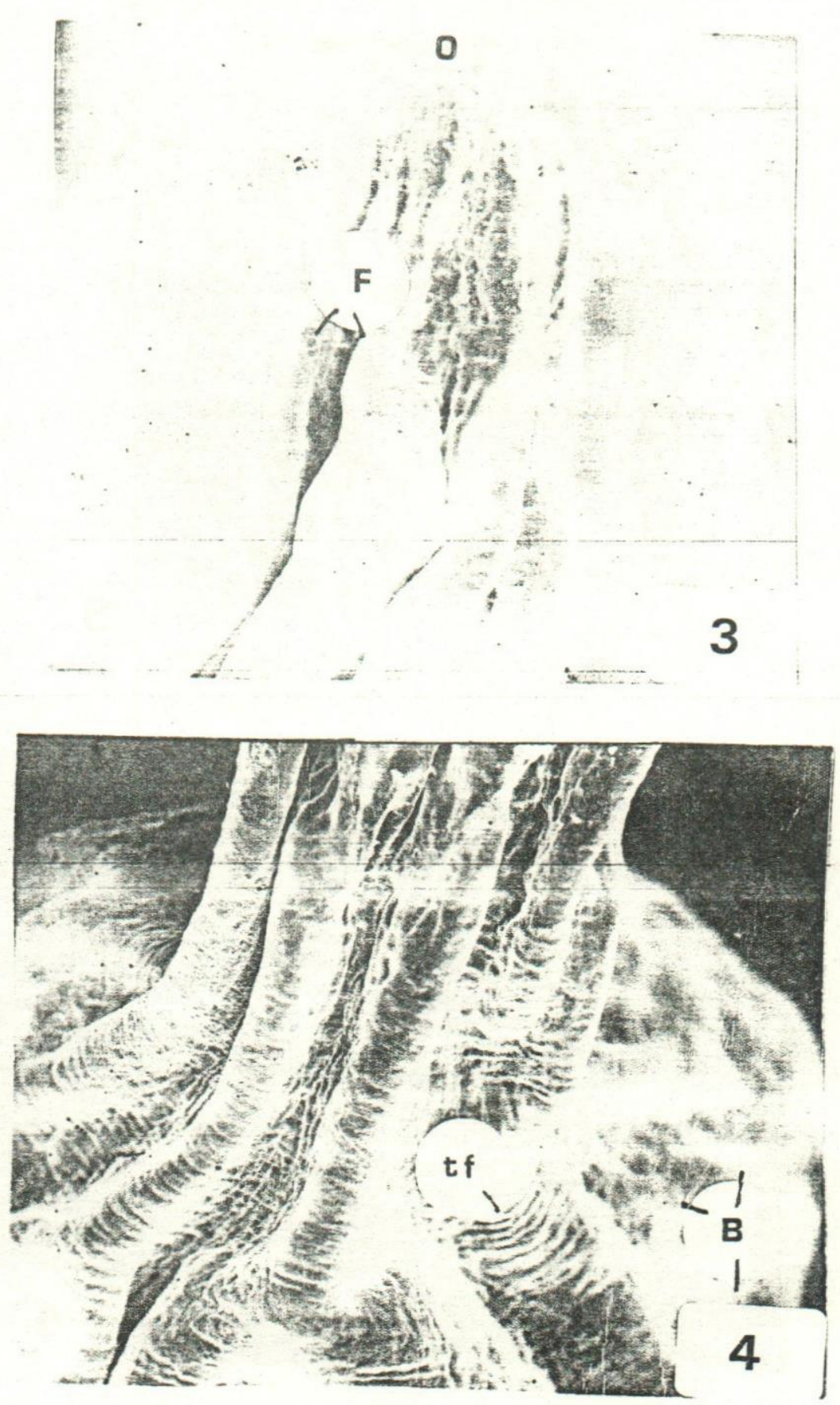
FATMA A. HIEKAL

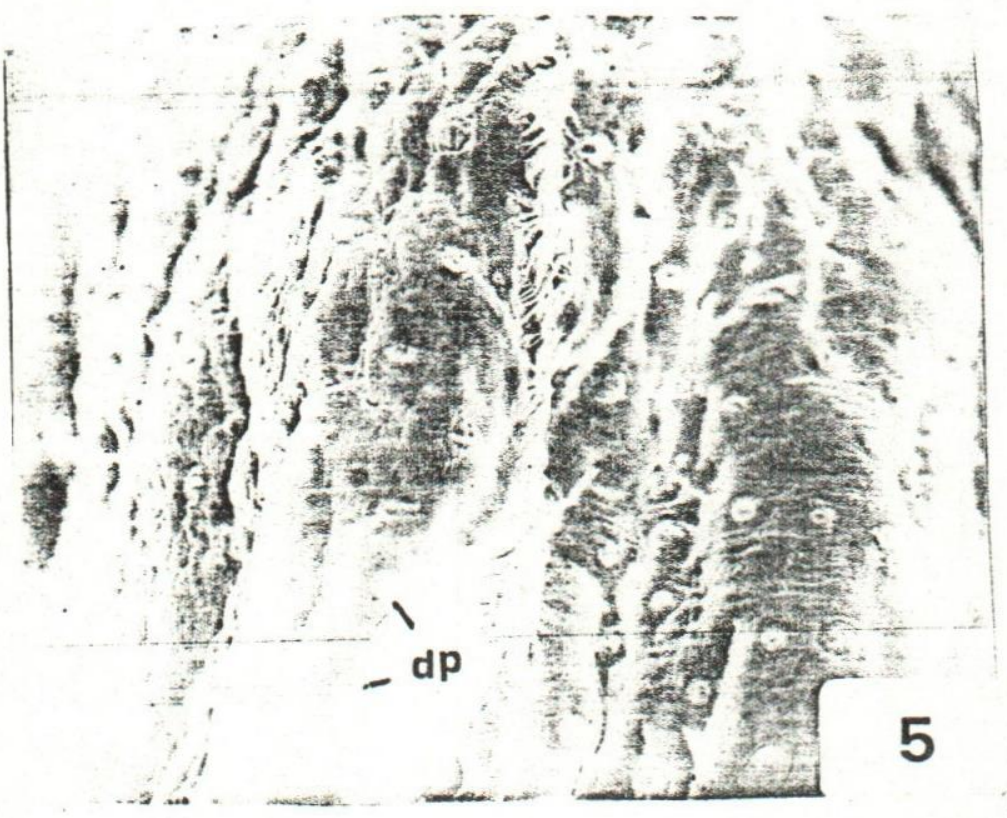

?

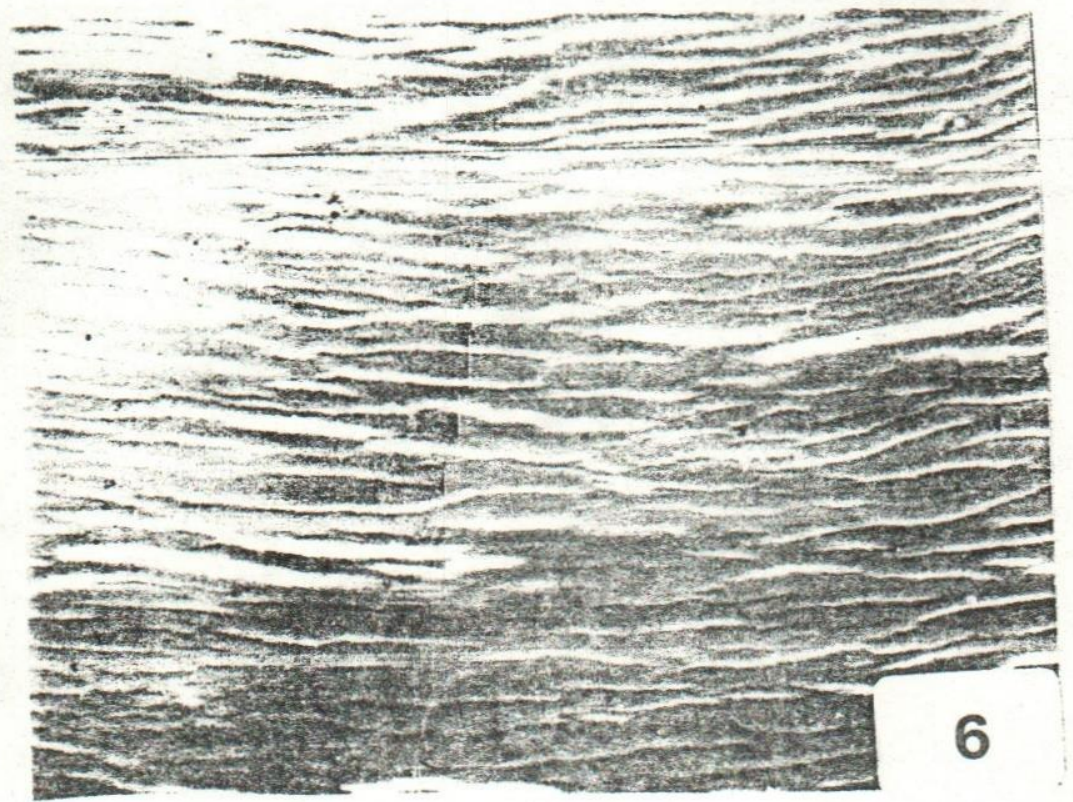

Assiut Vet.Med.J. Yol. 26, No. 52, January, 1992. 
SURF ACE TOPOGRAPHY, GASTRODISCUS AEGYPTIACUS
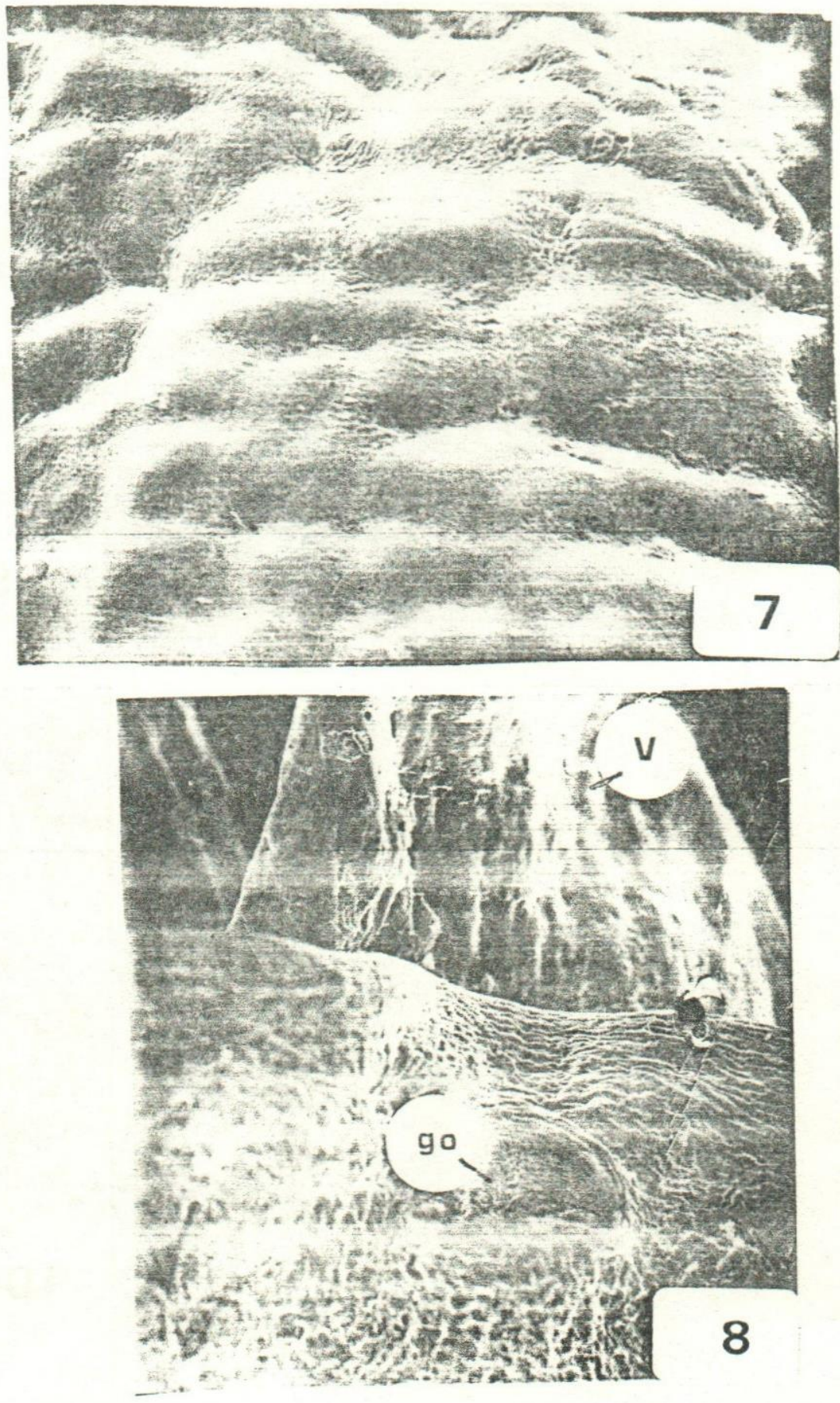

Assiut Vet.Med.J. Vol. 26, No. 52, January, 1992. 
FATMA A. HIEKAL
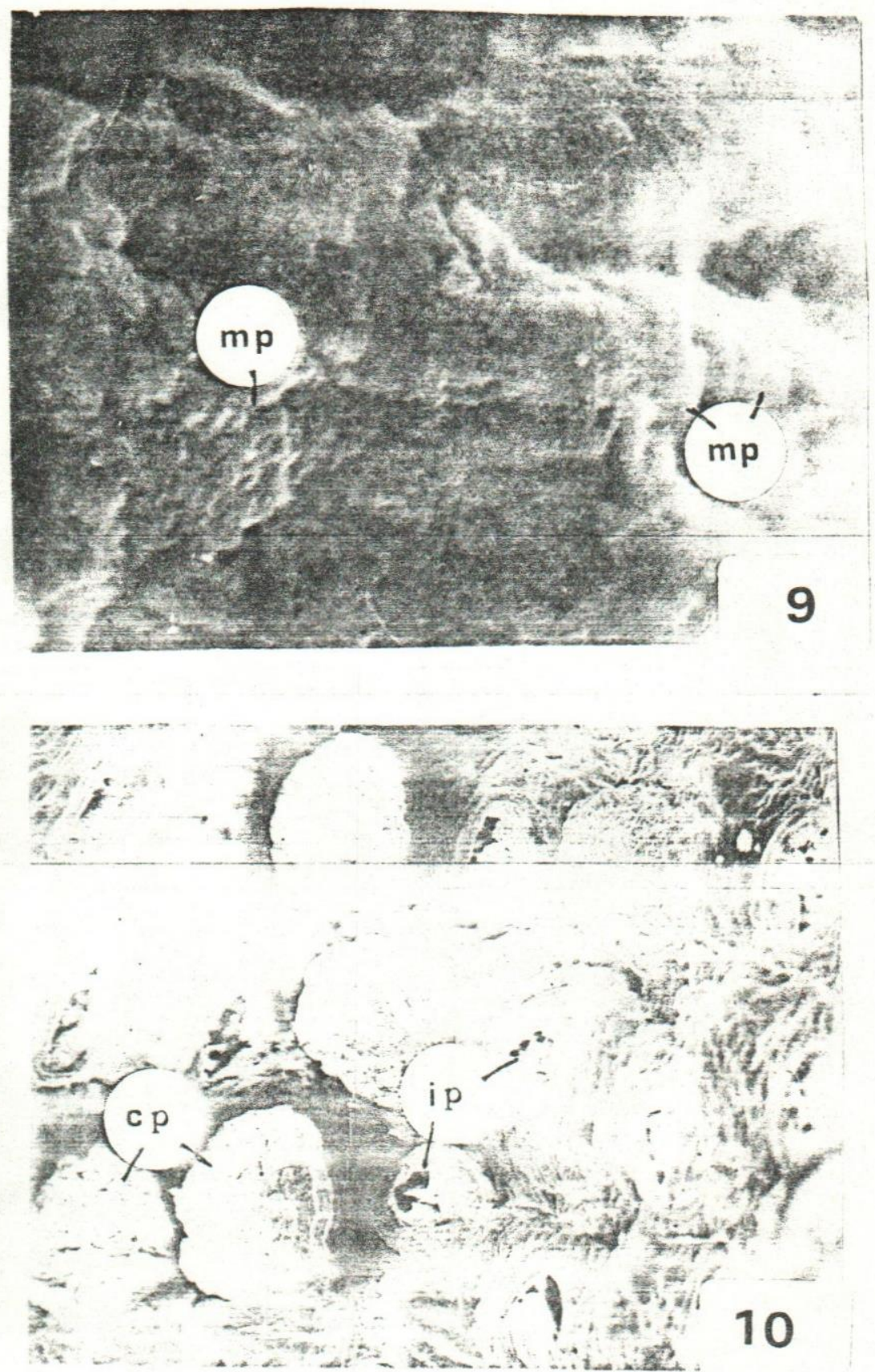
SURFACE TOPOGRAPHY, GASTRODISCUS AEGYPTIACUS
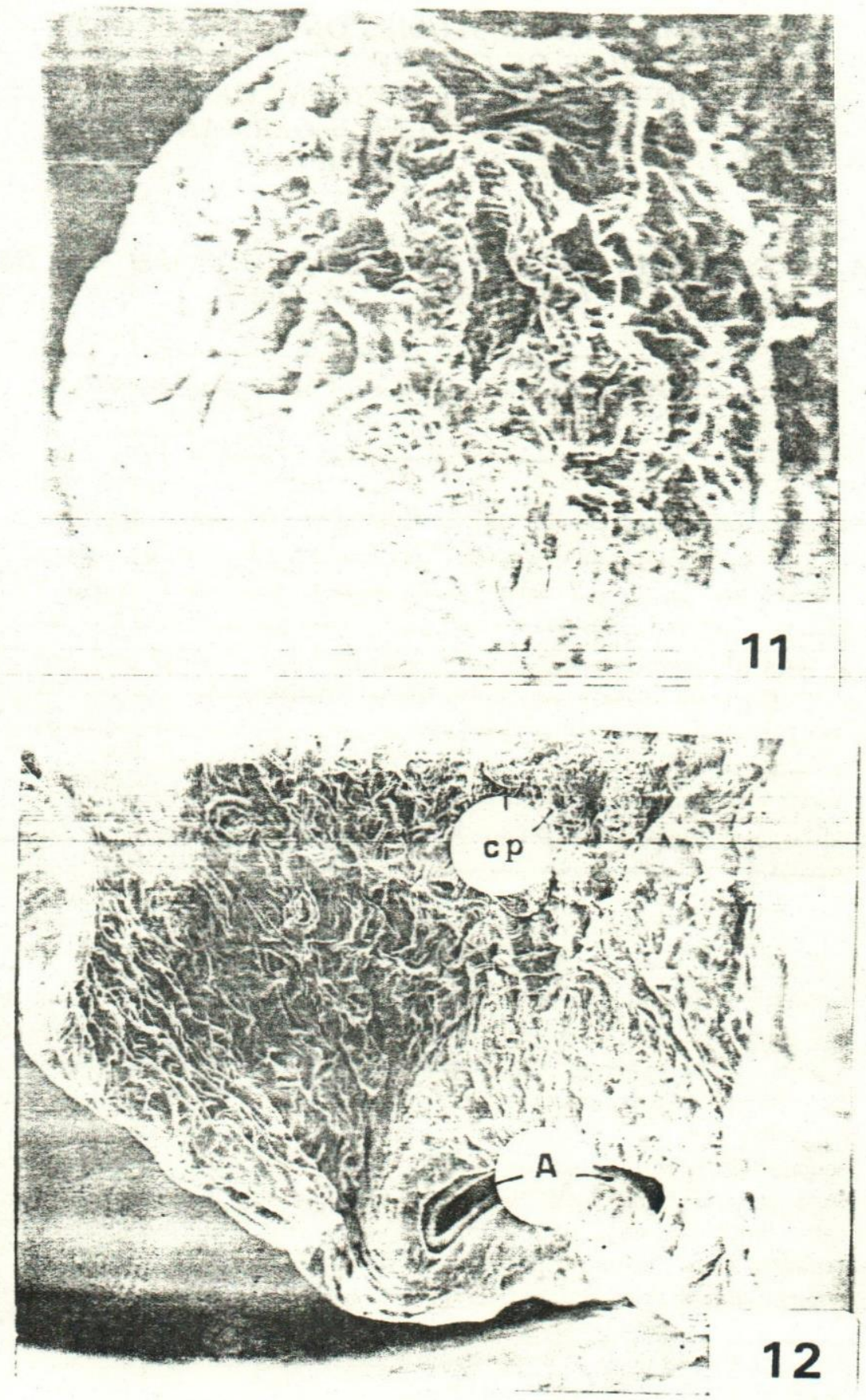

Assiut Vet.Med.J. Vol. 26, No. 52, Januarv, 1992. 